\title{
AFETIVIDADE E PRÁTICAS PEDAGÓGICAS NO ENSINO DE LÍNGUA INGLESA
}

\author{
Affectivity and pedagogical practices in English language teaching
}

\author{
Isabela Ramalho ORLANDO \\ Universidade Estadual de Campinas \\ isabelarorlando@gmail.com \\ https://orcid.org/0000-0001-9721-2402
}

Sérgio Antônio da Silva LEITE

Universidade Estadual de Campinas sasleite@uol.com.br https://orcid.org/0000-0003-2998-7112

\begin{abstract}
RESUMO: Neste trabalho, apresentam-se resultados de pesquisa, cujos objetivos foram identificar e analisar práticas pedagógicas de um professor que possam ter contribuído para a aproximação afetiva dos estudantes com a língua inglesa. A pesquisa fundamentou-se nas ideias de Vigotski (2009, 2012) e de Wallon (1979, 1995), além de seguir uma visão discursiva de linguagem (BAKHTIN, 2003; VOLOCHÍNOV, 2017). Assume-se que o processo de apropriação do conhecimento pelo estudante é mediado, sendo que a qualidade da mediação tem implicações nas relações que se estabelecem entre sujeito e objeto de conhecimento, as quais envolvem, indissociavelmente, as dimensões afetiva e cognitiva. A pesquisa foi realizada em um centro de línguas de uma universidade pública. Os resultados descrevem as atividades de ensino realizadas pela professora e as formas de participação dos estudantes, bem como suas percepções sobre elas. Os resultados indicam que a ampla variedade de atividades propostas pela professora possibilitou que os estudantes, mesmo que tivessem diferentes necessidades e expectativas, se envolvessem com o curso. A pesquisa dá indícios sobre como a relação sujeito-objeto é mediada, indicando a diversidade dessas formas de mediação na sala de aula observada, reafirmando-se a importância deste processo para construção das relações entre sujeito e objeto - as quais envolvem afeto e cognição simultaneamente.
\end{abstract}

PALAVRAS-CHAVE: Afetividade; Mediação; Ensino de língua inglesa.

ABSTRACT: This paper presents results of a research study, whose objectives were to identify and analyze a teacher's pedagogical practices that may have contributed to the affective approach of students with the English language. The research study was based on the ideas of Vigotski 
(2007, 2009) and Wallon (1979, 1995), and on a discursive view of language (Bakhtin, 2003, 2007). It is assumed that the process of knowledge appropriation by the student is mediated, and the quality of mediation has implications for the relationships established between subject and object of knowledge, which involve, inseparably, affective and cognitive contents. The research study was conducted in a language center at a public university. The results describe the teaching activities carried out by the teacher, and the way that students participated, as well as their perceptions about the activities. The results indicate that the wide variety of activities proposed by the teacher made it possible for students, even though they had different needs and expectations, to engage with the course. The research study gives evidence on how the subject-object relationship is mediated, indicating the diversity of these forms of mediation in the observed classroom, reaffirming the importance of this process for building the relationships between subject and object - which simultaneously involve affect and cognition.

KEYWORDS: Affectivity; Mediation; English language teaching.

\section{INTRODUÇÃO}

A afetividade esteve fora da pauta das pesquisas educacionais e das investigações sobre ensino de línguas durante muito tempo. Esta negligência com relação às questões sobre os afetos, no pensamento ocidental, deve-se, em grande medida, ao domínio secular da concepção dualista sobre o ser humano, a qual opõe razão e emoção, cognição e afeto, corpo e mente. A visão dualista tem suas raízes na Antiguidade, fortalecendo-se com o pensamento cartesiano, na idade moderna, e com o Positivismo, no período contemporâneo. Leite (2012) ressalta que, nesta perspectiva, principalmente após a Idade Média, a afetividade passou a ser considerada a dimensão inferior do ser humano em relação à razão - o que possibilitou o fortalecimento da corrente racionalista. No mesmo sentido, a emoção não poderia ser tomada como objeto de estudo, pois, devido ao seu caráter subjetivo, ela habitaria o mundo das ideias, inacessível ao olhar da ciência.

O dualismo do campo filosófico repercutiu também no campo da linguística aplicada, onde se observava um grande esforço para promover a razão, entendida como a maior conquista da humanidade, em detrimento das emoções, vistas com desconfiança durante séculos (RAJAGOPALAN, 2004). Tal realidade repercutiu na área da educação, o que pode ser percebido pela ausência da questão afetiva nos currículos escolares e nas pesquisas educacionais, até meados do século passado. Deve-se notar que tal relação 
também é percebida na área da educação linguística, campo abordado por este trabalho.

A visão dualista, entretanto, tem sido contestada ao longo da história, principalmente a partir do final do século XIX. No entanto, deve-se ressaltar que o pensamento de Spinoza foi fundamental na gênese das ideias que possibilitaram as bases da concepção monista do ser humano. Já no século XVII, Espinosa defendia que corpo e alma são atributos de uma substância única, assumindo que ambos seguem as mesmas leis (SPINOZA, 2017). Desta forma, o filósofo rompe a hierarquia secular que compreende a alma como superior ao corpo (LEITE, 2012).

No Brasil, durante as duas últimas décadas, o tema da afetividade tem sido objeto de estudo da Psicologia Educacional, em pesquisas que se afastam da visão dualista e buscam uma compreensão do ser humano em sua totalidade, assumindo uma visão monista, entendendo-se que as dimensões cognitiva e afetiva são indissociáveis no processo de desenvolvimento humano. Autores como Wallon (1979, 1995) e Vigotski (2009, 2012) fornecem as bases teóricas para esta concepção de investigação científica. Os estudos desses teóricos permitem inferir que o processo de desenvolvimento humano ocorre a partir das interações sociais, marcadas por conteúdos afetivos e cognitivos, que se influenciam mutuamente. Essas interações são determinantes para se entender o papel do processo de mediação na relação que o indivíduo estabelecerá com os diversos objetos e práticas culturais. Neste mesmo sentido, Wallon $(1979,1995)$ defende que a dimensão afetiva constitui as primeiras respostas emitidas pelo recém-nascido, constituindo, portanto, a base da estrutura psíquica a partir da qual o desenvolvimento humano ocorrerá.

O presente trabalho insere-se neste campo teórico, integrando as pesquisas desenvolvidas pelo Grupo do Afeto ${ }^{1}$, que, nas últimas duas décadas, tem se dedicado ao estudo da afetividade nas práticas pedagógicas desenvolvidas pelos professores. Este texto baseia-se em uma pesquisa (ORLANDO, 2019) ${ }^{2}$ que, com base em dados coletados em sala de aula, procurou identificar e analisar práticas pedagógicas que possam ter contribuído para a aproximação dos estudantes com a língua inglesa, pressupondo que esta aproximação envolve tanto conteúdos cognitivos como afetivos. Para cumprir este

\footnotetext{
${ }^{1}$ O Grupo do Afeto é parte integrante do Grupo de Pesquisa ALLE/AULA, da Faculdade de Educação da Unicamp.

${ }^{2}$ Financiada pela FAPESP (Processo no 17/00588-9); aprovado pelo Comitê de Ética da Unicamp (Número do CAAE: 69384017.1.0000.5404).
} 
objetivo, inicialmente, são apresentadas, resumidamente, as bases teóricas que fundamentam a pesquisa; em seguida, expõem-se os procedimentos de coleta e análise dos dados; por fim, são apresentados os principais resultados da pesquisa, os quais descrevem as atividades de ensino desenvolvidas pela professora em sala de aula, relatando como elas eram conduzidas pela docente, bem como as formas de participação dos estudantes.

\section{AFETIVIDADE E PRÁTICAS PEDAGÓGICAS}

O desenvolvimento do ser humano, bem como a constituição de sua subjetividade, se dá nas e pelas relações sociais, por meio da apropriação da cultura. Compreende-se, com base nas ideias de Vigotski $(2009,2012)$ e de Wallon $(1979,1995)$, que esse processo engloba tanto conteúdos afetivos quanto cognitivos. Vigotski (2012) afirma que a gênese do desenvolvimento é social, ou seja, inicia-se no plano interpsicológico para, então, passar para o plano intrapsicológico. Wallon $(1979,1995)$, por sua vez, indica que é por meio do contato com o outro que o indivíduo se percebe como pessoa, isto é, como um ser único. Ambos autores sustentam, portanto, que o desenvolvimento humano depende, fundamentalmente, das relações sociais e de sua inserção e participação na cultura.

Vigotski (2012) defende que o desenvolvimento das funções psicológicas superiores, tipicamente humanas, depende da apropriação dos elementos culturais. $\mathrm{O}$ autor assume que a relação entre o ser humano e o mundo não é direta, ou seja, não se dá pela simples relação estímulo-resposta, mas é, na verdade, mediada por instrumentos e signos, que são construídos em um processo histórico e social. Isto significa que o indivíduo apropria-se dos elementos da cultura por meio da interação com o outro e que sua relação com o mundo ocorre através da intervenção de sistemas simbólicos, fornecidos pela própria cultura, como, por exemplo, a linguagem.

Neste sentido, cabe lembrar que a linguagem é o sistema simbólico básico dos grupos humanos e, conforme indica Vigotski (2009), ela expressa claramente a natureza histórica da consciência humana. O autor dedicou-se profundamente ao estudo da relação entre pensamento e linguagem, afirmando que a unidade dessa relação é o significado da palavra. Isso quer dizer que o significado da palavra é tanto um fenômeno do pensamento quanto fenômeno do discurso (VIGOTSKI, 2009). Esta discussão guarda relação também com o estudo da afetividade, uma vez que se compreende que o sentido da palavra 
relaciona seu significado, partilhado pela cultura, às experiências individuais vivenciadas pelo sujeito, carregando marcas afetivas e pessoais. Por isto, o sentido é relacionado à subjetividade humana.

Wallon $(1979,1995)$ constrói uma visão monista do ser humano ao explicar o desenvolvimento por meio da integração dialética entre os campos motor, cognitivo e afetivo, os quais compõem o quarto campo - a pessoa. Baseado em suas pesquisas e observações, o autor identifica cinco estágios no processo de desenvolvimento humano, até a adolescência/puberdade. $\mathrm{O}$ autor assinala a importância da afetividade nesse processo, indicando que ambas - afetividade e cognição - são constituintes de todas suas fases de maneira indissociável, observando-se uma alternância de predomínio entre elas.

Wallon (1979) define afetividade como um conjunto amplo de manifestações, que engloba as emoções, de origem biológica, e os sentimentos, de origem psicológica. A afetividade desenvolve-se com a apropriação dos sistemas simbólicos pelo sujeito, o que possibilita a capacidade de fantasiar, imaginar, criar, planejar, entre outras. Além disto, o conjunto afetivo sinaliza como o ser humano é afetado pelo mundo (MAHONEY; ALMEIDA, 2004). Observa-se, portanto, a integração entre os campos funcionais, uma vez que Wallon afirma que ser afetado pelo mundo estimula tanto os movimentos do corpo quanto a atividade mental.

Tomando como base teórica os autores expostos acima, os membros do Grupo do Afeto têm realizado, nos últimos vinte anos, pesquisas a fim de compreender como os afetos inserem-se e constituem o processo de ensino-aprendizagem. O conjunto de pesquisas do Grupo do Afeto, embora abranja diferentes situações e níveis de ensino, segue alguns princípios teóricos em comum. O primeiro deles é o pressuposto de que o processo de apropriação do conhecimento parte da relação entre sujeito e objeto. Essa relação, por sua vez, é sempre mediada por agentes culturais, sejam eles pessoas físicas ou produtos culturais. Compreende-se ainda que as relações entre sujeito - objeto de conhecimento - mediador são marcadamente afetivas. Com isto, assume-se que a qualidade da mediação vivenciada pelo sujeito é determinante do tipo de relação que este estabelecerá entre ele - sujeito - com o objeto de conhecimento, sendo que esta relação envolve, simultaneamente, as dimensões afetiva e cognitiva (LEITE, 2012).

$\mathrm{Na}$ sala de aula, o professor, por meio das decisões que assume no planejamento e 
execução de sua prática pedagógica, influencia fortemente na trama de relações que dão forma à vida afetiva dos estudantes, especialmente em face ao conhecimento. Neste sentido, foram identificadas cinco decisões básicas assumidas pelo professor que, pelos dados das pesquisas do Grupo do Afeto, têm implicações afetivas nas relações que se estabelecem entre o aprendiz e o objeto de conhecimento (LEITE, 2018). São elas: a escolha dos objetivos de ensino; o ponto de partida do ensino; a identificação e a organização dos conteúdos; a escolha dos procedimentos e atividades de ensino; e a escolha dos procedimentos de avaliação. Obviamente, tais decisões não esgotam todos os fatores que afetam o processo de ensino-aprendizagem. No entanto, as pesquisas do Grupo do Afeto sugerem que a coerência entre essas cinco decisões, na concretização do planejamento em sala de aula, têm favorecido relações de aproximação entre os estudantes e os diversos objetos de conhecimento, ao se considerar que estas relações são, indissociavelmente, afetivas e cognitivas.

\section{Afetividade e práticas pedagógicas: as particularidades do ensino de línguas}

Neste trabalho, a língua inglesa não é entendida como língua neutra ou língua universal. Pelo contrário, destacam-se os processos ideológicos pelos quais se tenta promover o inglês como língua global, como o apagamento das contradições de sua expansão, esquecendo que sua hegemonia é força de exclusão social e política de inúmeras outras línguas (RODRIGUES, 2011). Pennycook (1994) afirma que muitos povos e culturas são silenciados e apagados por meio da expansão da língua inglesa no mundo e da idealização da Inglaterra e dos Estados Unidos como referências. Portanto, a sala de aula de língua coloca-se como um espaço onde é possível deslocar o discurso hegemônico de determinados países e dar espaço à pluralidade de línguas e culturas.

No âmbito deste estudo sobre afetividade, estas questões, inerentes ao processo de ensino-aprendizagem de línguas, devem ser levadas em consideração. Isto porque a língua, além de ser objeto de conhecimento, é também constitutiva da subjetividade humana, como lembram Quast e Banks-Leite (2011); com isto, coloca-se também como instrumento ideológico e de controle de poder. Desta forma, a afetividade, além de relacionar-se com a produção do conhecimento no processo de ensino-aprendizagem, apresenta uma nova faceta: a questão discursiva. 
Assumir uma visão discursiva de linguagem, isto é, orientar-se por premissas bakhtinianas, implica em, ao se pensar a constituição do sujeito, compreender que "a consciência social é um fato social e ideológico" (VOLOCHINOV, 2017, p. 97). Para Bakhtin e o círculo é o material sígnico, criado na comunicação social, que forma e realiza a consciência. Isto significa que a linguagem é central na constituição dos sujeitos e da realidade. A linguagem, por sua vez, precisa ser reconhecida por sua natureza dialógica e por seu movimento dialético incessante de tensão e determinação entre social e o individual, entre Eu e Outro, que permeia as relações humanas.

Com isto, colocam-se questões acerca das relações entre linguagem - entendida em seu caráter discursivo e dialógico - e subjetividade. Questiona-se, portanto, o que significa, deste ponto de vista, o êxito na aprendizagem de uma língua estrangeira. $\mathrm{O}$ Grupo do Afeto tem, por meio dos resultados de anos de pesquisa, questionado os sentidos de uma aprendizagem bem-sucedida (LEITE, 2018). A forma como o grupo tem compreendido esta questão é esclarecida por Leite (2018):

\begin{abstract}
O processo de ensino-aprendizagem de sucesso caracteriza-se por um duplo movimento: possibilita ao aluno apropriar-se do objeto do conhecimento, de forma ativa e autônoma e, simultaneamente, possibilita ao aluno estabelecer vínculo afetivo positivo com o mesmo, ou seja, promove um movimento de aproximação com o objeto, de natureza essencialmente afetiva (LEITE, 2018, p. 21).
\end{abstract}

Há uma implicação pedagógica clara e importante neste posicionamento do Grupo do Afeto: não se considera mais viável, do ponto de vista ético e psicológico, o controle punitivo dos processos de aprendizagem, uma vez que esses, embora possam promover o aprendizado, ao se considerar somente a nota do aluno, promovem também o afastamento afetivo do aluno em relação ao objeto de estudo (LEITE, 2018).

De forma semelhante, também considerando-se um referencial teórico vigotskiano, Swain, Kinnear e Steinman (2011) questionam o que significa uma aprendizagem de línguas bem-sucedida: "o que é sucesso na aprendizagem de língua? É apenas usar a língua com precisão, ou inclui sentir-se bem sobre si mesmo como usuário da língua e como membro da comunidade linguística?” (Edição Kindle, capítulo 5).

Neste sentido, defende-se, juntamente com Rajagopalan (2004) e Swain (2013), 
que é preciso voltar o olhar para as emoções ${ }^{3}$ no campo de estudos da linguagem e do ensino de línguas. Isto porque, como indica Swain (2013), as emoções têm sido o “elefante no quarto" nas pesquisas sobre ensino de línguas: todos sabem que elas estão lá, mas ninguém se arrisca a falar sobre elas. Considerando-se que as questões afetivas têm implicações significativas sobre a aprendizagem de línguas, justifica-se a necessidade de investigações sobre o tema, especialmente partindo de uma concepção social (e não individualista) das emoções (SWAIN, 20013). A presente pesquisa coloca-se, desta forma, como uma contribuição a este vasto campo a ser explorado.

\section{DECISÕES METODOLÓGICAS}

A pesquisa, de caráter qualitativo com características etnográficas, foi realizada em um centro de língua de uma universidade pública do estado de São Paulo. Buscou-se, intencionalmente, uma professora de inglês que fosse reconhecida pela comunidade alunos e professores - como uma excelente professora e, por meio de indicações, encontrou-se a professora Lúcia $^{4}$. Desta forma, os participantes da pesquisa foram a professora e os vinte e três estudantes da turma de Inglês IV, na referida instituição. Os estudantes vinham de diversos cursos de graduação, sendo apenas dois deles estudantes de pós-graduação, ressaltando-se que todos faziam a disciplina em caráter não obrigatório.

A pesquisadora acompanhou o desenvolvimento da disciplina durante todo o semestre, registrando as aulas por meio de videogravação e diário de campo. Além disto, foram realizadas minientrevistas com estudantes, antes ou depois das aulas, a fim de conhecer suas opiniões e impressões em relação às atividades promovidas pela professora, bem como ter acesso às suas histórias com a aprendizagem da língua inglesa. Ao final do semestre, foi realizada uma entrevista com a professora, na qual se resgatou sua história de constituição como professora - descrita em Orlando e Leite (2018) - e suas concepções sobre ensino de língua inglesa.

No momento da realização da pesquisa, a professora Lúcia já havia se aposentado e trabalhava no Centro de Línguas como professora colaboradora. Os estudantes, quando a

\footnotetext{
${ }^{3}$ Estes autores não diferenciam os termos emoções e afetos, tal como faz Wallon, conforme já explicitado anteriormente. Aqui, manteve-se o termo emoção por ter sido assim utilizado pelos autores citados.

${ }^{4}$ Para preservar a identidade dos participantes, foram utilizados nomes fictícios.
} 
descreviam, destacavam sua receptividade na relação com a turma, indicando que a professora era atenciosa e procurava conhecer cada membro do grupo. Outra característica de Lúcia, que era muito realçada pelos estudantes, era sua alegria em relação à docência, isto é, percebia-se a paixão da professora pela profissão. Analisando-se a entrevista com a professora, em contraste com as atividades desenvolvidas em sala de aula, destaca-se, ainda, a coerência entre os referenciais teóricos assumidos por ela e sua prática pedagógica.

Para fins de análise, os dados gerados na pesquisa de campo foram organizados em atividades de ensino. Esta escolha metodológica deveu-se à percepção, ainda durante o período de observação das aulas, de que um dos traços da prática pedagógica de Lúcia era a grande diversidade de atividades desenvolvidas, o que se confirmou após a leitura extensiva dos dados.

Outras pesquisas no campo da afetividade debruçaram-se sobre atividades de ensino, com destaque para a realizada por Garzella (2013). De forma semelhante, no âmbito deste trabalho, o conceito de atividade de ensino é entendido como um processo que se desenvolve na relação professor-aluno. A fim de determinar um parâmetro teórico para a análise dos dados, podem-se identificar três aspectos inter-relacionados que caracterizam uma atividade de ensino: a) instrução, que diz respeito às instruções fornecidas pelo professor ou por um colega para a realização de uma atividade pelo estudante; b) desenvolvimento, que se refere à execução da atividade pelo estudante, onde se preveem intervenções necessárias e adequadas do professor; c) feedback, que consiste no retorno do professor sobre a atividade realizada pelo aluno ou sobre o produto dela e pode incluir correções, informações, incentivos, com objetivo de levar o estudante a compreender a qualidade de seu trabalho, identificar possíveis problemas e superá-los. Devido ao aspecto dinâmico da sala de aula, as atividades de ensino não ocorrem de maneira linear, como acima exposto. É possível, por exemplo, que o professor dê novas instruções durante o desenvolvimento de uma atividade, caso o aluno apresente dificuldades para executá-la. Ou ainda pode haver correções ao longo da realização de um trabalho (GARZELLA, 2013).

Com este modelo teórico sobre atividade de ensino, realizou-se a análise dos dados, que compreendeu as seguintes etapas: a) análise do diário de campo, identificando 
os diferentes tipos de atividades e destacando todas suas ocorrências; b) revisão das aulas gravadas, a fim descrever como foi realizada cada ocorrência de um determinado tipo de atividade; c) transcrição, na íntegra, de ao menos um exemplo de cada tipo de atividade; d) análise das entrevistas com estudantes, em busca de falas sobre determinada atividade; e) análise da entrevista com a professora, identificando falas sobre as atividades.

Ao final da análise, foram identificados dez tipos de atividades, sendo assim nomeadas: 1- Leitura; 2- Listening (Compreensão oral); 3- Gramática; 4- Conversação; 5Produção escrita; 6- Vocabulário; 7- Pronúncia; 8- Workshop "Saving Indegenous Languages in Western Amazonia"; 9- Filmes, vídeos e músicas; 10- Avaliação. Neste artigo, serão apresentadas, resumidamente, as dez atividades de ensino e será destacado aquilo que se observou de mais relevante em cada uma delas. Desta maneira, a análise dos dados pretende responder ao objetivo assumido na pesquisa - investigar as práticas pedagógicas da professora e suas implicações nas relações entre estudantes e objeto de conhecimento - ao descrever as atividades de ensino desenvolvidas.

\section{AS ATIVIDADES DE ENSINO: ANÁLISE E DISCUSSÃO DO DADOS}

Com base nas observações das aulas e nas entrevistas com estudantes e com a professora, serão apresentadas, sinteticamente, as atividades de ensino elencadas anteriormente, evidenciando como cada uma delas afetava os estudantes. Para isso, seguese uma breve descrição de como a professora desenvolvia a atividade de ensino e, em seguida, trechos das falas dos estudantes sobre elas ou trechos de situações de sala de aula.

\section{Leitura}

Atividades cujo foco era leitura de textos em inglês, do material didático ou de outras fontes como jornais, blogs e redes sociais, geralmente seguidas de exercícios sobre a leitura e/ou discussão do material. Muitas vezes, os textos contextualizavam questões de gramática, vocabulário e pronúncia que seriam trabalhadas posteriormente. A professora frequentemente fazia uma pequena introdução ao tema que seria abordado no texto, utilizando diferentes recursos, como exibição de trechos de filmes e séries, colocando questões aos estudantes ou expondo, ela mesma, algum ponto que seria visto na leitura. 
Muitas vezes, era solicitado aos estudantes que fizessem uma primeira leitura do texto em casa, bem como a resolução de alguns exercícios sobre ele e, em sala, o conteúdo era corrigido e aprofundado.

A estratégia adotada pela professora nas atividades de leitura - pedir que os estudantes lessem os textos e respondessem aos exercícios em casa - dava-lhes a possibilidade de investir na tentativa de compreensão daquele material. Já o que era feito coletivamente em sala - leitura e correção dos exercícios - apresentava-se como um fechamento deste trabalho, que havia sido iniciado individualmente, sendo que os estudantes podiam expor suas interpretações e sanar dúvidas. Sobre as atividades de leitura, Giovana afirmou:

Eu gosto quando tem que ler texto e interpretar, sabe? Quando tem aqueles textos grandes, eu gosto! Porque, a maioria das vezes, eu entendo tudo. Eu fico feliz, satisfeita. ${ }^{5}$

Esta fala indica o prazer da estudante ao ler um texto e sentir-se capaz de compreendê-lo, o que era, em grande medida, proporcionado pelas estratégias de ensino adotadas pela professora. Leite (2018) mostra que esse sentimento de "sentir-se capaz de" é um ponto importante na construção de relações afetivas entre sujeito e objeto de conhecimento.

\section{Listening (compreensão oral)}

Este tópico trata das atividades, propostas no livro didático, que envolviam a escuta de áudios em inglês e a realização de exercícios de compreensão e interpretação. A professora costumava sugerir aos estudantes que lessem o enunciado dos exercícios antes de ouvirem o áudio. Deste modo, os estudantes teriam uma ideia prévia do que seria abordado no áudio e, no momento em que esse estivesse sendo tocado, poderiam concentrar-se em ouvir, sem se preocupar com a leitura dos enunciados. Além disto, a professora também dava instruções claras sobre os exercícios, o que podia ser percebido pela baixa manifestação de dúvidas dos estudantes, bem como pelo fato de eles corresponderem adequadamente às instruções. Vale destacar que, além dos áudios trazidos pelo livro didático, a professora levava outros materiais para os estudantes ouvirem, mas

\footnotetext{
${ }^{5}$ Os dados apresentados podem ser encontrados em Orlando (2019).
} 
esses serão discutidos na atividade de ensino "Filmes, vídeos e músicas".

Dentre tais atividades, destacou-se um ponto da prática pedagógica da professora Lúcia: a possibilidade de negociação de sentidos no diálogo entre estudantes e professora. Isso pode ser observado no trecho a seguir, em que os estudantes e a professora discutem sobre um áudio que haviam escutado para a realização de exercícios de interpretação:

Quadro 1: Trecho de atividade em sala de aula:

\begin{tabular}{|c|c|}
\hline Descrição da atividade & Inferências \\
\hline $\begin{array}{l}\text { Professora: Are you sure? You have to be in } \\
\text { good shape, yes... Em forma... You don't have } \\
\text { to be an athlete, but you have to be in shape. } \\
\text { You have to be physically fit... I don't know... } \\
\text { Aurora: Ela diz que tem que ser ativo... } \\
\text { Professora: Então, mas se você está ativo, } \\
\text { você está em forma... } \\
\text { (Estudantes olham com expressão de } \\
\text { discordância) } \\
\text { Professora: Não? Não necessariamente? } \\
\text { Então é false! Then it's false. What do you } \\
\text { understand by active? (...) }\end{array}$ & $\begin{array}{l}\text { Há uma discordância sobre a resposta da } \\
\text { última frase, professora busca explicar o que } \\
\text { é "good shape". } \\
\text { Aurora diz que, no áudio, a entrevistada fala } \\
\text { que as pessoas têm que ser ativas, indicando } \\
\text { que ela compreende "pessoa ativa" e "pessoa } \\
\text { em boa forma" como coisas distintas. Outros } \\
\text { estudantes parecem concordar. } \\
\text { Professora diz que, já que eles entendem de } \\
\text { outra forma, então eles podem marcar a } \\
\text { questão como falsa. }\end{array}$ \\
\hline
\end{tabular}

Fonte: ORLANDO, 2019, p. 234.

Este excerto mostra que a professora viabilizava espaço para interpretação dos estudantes. Quando houve divergência sobre o que significa "pessoa ativa", ela permitiu que os estudantes respondessem à questão de acordo com suas definições. Ou seja, ela não se prendeu a um sentido pré-estabelecido do texto escutado e, além disto, interessou-se em saber como os estudantes entendiam a expressão e ouviu atenciosamente o que eles compreendiam por "pessoa ativa".

Quast e Banks-Leite (2011) apontam que, na aula de línguas, é preciso dar espaço para processos intersubjetivos, dinâmicos e dialógicos, que contribuam para a produção de significados/sentidos. As autoras afirmam que uma verdadeira aprendizagem "implica produção (dialógica) dos sentidos, transformação, (re)elaboração" (p. 185), em processos permeados pelas emoções. $\mathrm{O}$ espaço que a professora Lúcia disponibiliza às interpretações dos estudantes possibilita que eles entrem em diálogo com ela. Além disto, compõe um acolhimento não-autoritário que facilita as relações dos estudantes com a língua inglesa. 
Com isto, os estudantes são convidados a produzir novos enunciados e não são obrigados, simplesmente, a copiar o discurso que vem da professora ou do livro didático.

\section{Gramática}

Nesta subseção retrata-se a forma como a professora apresentava e explicava os conteúdos de gramática. Esses conteúdos eram, frequentemente, contextualizados por textos ou áudios do livro didático. Em geral, a professora utilizava os exemplos trazidos no livro para iniciar sua explicação, além de utilizar a lousa para destacar a formação de determinadas estruturas, dando uma pequena aula expositiva sobre o conteúdo, durante a qual introduzia novos exemplos. Em seguida, a professora costumava passar exercícios em que os estudantes pudessem praticar o conteúdo que acabara de ser explicado - que poderiam ser extraídos do livro didático, de outros livros trazidos ou elaborados por ela mesma. Era comum a professora propor tarefas em que os estudantes trouxessem elementos das suas vidas e experiências pessoais para abordar novas estruturas gramaticais. Frequentemente essa parte prática adquiria um caráter mais interativo, com o uso de jogos ou dinâmicas. Exercícios de gramática também foram solicitados como tarefa de casa e eram corrigidos coletivamente em sala.

Os estudantes demonstravam-se satisfeitos com a forma como a professora explicava esses conteúdos, o que pode ser percebido pela fala de Aurora:

E faz sentido a forma como ela explica, não é só mecânico, sabe? Por exemplo, a forma como ela explicou lá do Present Perfect. Faz muito mais sentido ela explicar que é uma ação, que aconteceu no passado, mas que o efeito ainda é presente. Quando você entende o funcionamento da língua, a gramática faz mais sentido e você não esquece, do que só quando te passam as regrinhas de gramática, sabe. Eu acho que isso que me ajudou: entender o funcionamento da língua, que ela sempre explica isso. (Aurora).

Além das explicações claras, foi elogiada, nas entrevistas, a possibilidade de se colocarem em prática os conteúdos aprendidos. Os estudantes destacaram as atividades em duplas ou em grupos, nas quais eles eram levados a utilizar as construções aprendidas ao conversar sobre temas e experiências pessoais. Neste tópico, pode-se evidenciar, ainda, uma questão importante no estudo da afetividade, que é o fato de as pessoas serem afetadas de formas diferentes por uma mesma situação ou prática. A maioria dos 
estudantes mostrou-se satisfeita com a forma das explicações de gramática e também com a quantidade delas, mas houve uma estudante que relatou que gostaria que esse tópico tivesse sido mais enfatizado ao longo do curso. Essas diferenças são esperadas e, geralmente, é possível compreendê-las melhor quando se conhece a história do sujeito. No caso dessa estudante, por exemplo, ela havia relatado que procurou o curso de inglês da universidade com a expectativa de superar lacunas de aprendizagem que apresentava em seu repertório, relacionadas aos tópicos gramaticais, fruto de experiências anteriores de aprendizado da língua.

\section{Conversação}

Nas aulas da professora Lúcia, as atividades de conversação ocupavam um lugar central. Deve-se destacar que todas as atividades de ensino, aqui apresentadas separadamente para fins de análise, eram conectadas umas às outras. Neste sentido, as atividades de conversação foram, em diversas ocasiões, utilizadas como continuidade de outras atividades, tais como após leitura de textos ou atividades de Listening, que poderiam disparar um tópico para a conversação ou seguindo explicações gramaticais, como forma de cristalizar o uso de determinado conteúdo.

Era comum que a professora relacionasse os temas estudados nas aulas com experiências pessoais dos alunos. Por exemplo, quando haviam lido um texto sobre prédios antigos, a professora pediu que eles conversassem sobre prédios históricos de suas cidades natais. A partir das entrevistas, observa-se que esta dinâmica era muito apreciada pelos estudantes.

(...) qualquer lugar que a gente fosse, talvez em outro país, a gente ia falar dessas coisas que a gente fala aqui. Por exemplo, falaria da nossa vida, de onde a gente veio, então isso tá forçando a gente a falar essas coisas, essas frases. E, cada vez que a gente fala, deixa de ser difícil falar aquilo. Então, se eu for para outro país, eu vou falar aquelas minhas palavras; quando eu conhecer novas pessoas, eu vou falar aquilo de novo. E eu acho que as coisas que eu tô aprendendo em inglês - que eu tô falando sem pensar - são coisas que eu já falei várias vezes. Então, eu acho que é por aí mesmo. (Miguel).

Miguel destacou que falar sobre aspectos de sua vida e de suas experiências 
pessoais the daria a oportunidade de praticar aquilo que chamou de "minhas palavras", o que ele acreditava ser importante em seu aprendizado da língua. Além disso, estas atividades oportunizavam que os estudantes se conhecessem melhor e criassem vínculos entre si. Ao longo do curso, foi possível notar que as relações entre os estudantes, intencionalmente fortalecidas pela professora, também potencializaram o aprendizado da língua e a construção de boas relações com esse objeto.

\section{Produção escrita}

Trata-se de atividades cujo objetivo era produção de textos escritos pelos estudantes. A maioria de tais atividades foi realizada em ambiente virtual de aprendizagem da universidade, portanto, não se teve acesso tão amplo a estas tarefas quanto às demais. Em geral, a professora Lúcia explicava a proposta da atividade em aula e, posteriormente, postava as instruções na plataforma virtual da universidade. Os estudantes eram solicitados a escrever seus textos em um documento do Word e deveriam postá-los na mesma plataforma até uma data estipulada pela professora. Depois disto, a professora fazia a correção dos textos, utilizando as ferramentas do Word, e realizava a devolutiva aos estudantes. Durante o período em que a professora corrigia os textos, ela também apresentava, em sala de aula, comentários gerais sobre as produções.

Além disto, foi realizada uma atividade, em sala de aula, sobre a escrita de parágrafos. $\mathrm{Na}$ ocasião, a professora perguntou aos estudantes quais foram os tópicos sobre produção de texto que eles haviam aprendido em suas aulas de português, durante o Ensino Médio. Com isso, ela tentou estabelecer uma ponte entre os conhecimentos prévios dos estudantes e aquilo que seria estudado em sala de aula. A esse respeito, destaca-se como a língua materna pode apoiar a aprendizagem da língua estrangeira. A professora Lúcia utilizava esta relação de forma adequada: mobilizava conhecimentos dos estudantes e, verificando aquilo que eles já sabiam sobre produção escrita, introduziu o conteúdo -no caso, o ensino sobre a organização de parágrafos.

Quanto às produções escritas realizadas pelos estudantes no ambiente virtual, foi destacada a relevância das temáticas escolhidas pela professora. João lembra, por exemplo, de terem escrito uma cover letter - carta que acompanha o currículo:

Eu acho legal também que ela trouxe material... aplicável. Por exemplo, ela vai 
falar de fazer o currículo, ajudou na carta. Essas coisas eu acho legal. (...) É bom, porque às vezes a gente tem que fazer, mas não tem noção de como tem que ser. Aí, só de ter uma pessoa que vai ler com atenção e falar o que tá bom, o que tá ruim, já... é bom. (João).

Por fim, deve-se salientar que o feedback é parte fundamental de uma atividade de ensino. A professora fornecia, de forma muito adequada, feedback individual detalhado para cada estudante sobre seus textos. Além disto, ela fazia comentários gerais em sala de aula, a partir da generalização das principais dificuldades dos alunos que ela havia observado durante suas correções. Desta forma, possibilitava que os alunos compreendessem seus erros, aperfeiçoassem sua escrita e avançassem para a aprendizagem de temas mais complexos.

\section{Vocabulário}

Apesar de as questões de vocabulário surgirem ao longo das outras atividades, havia também um tipo de atividade cujo objetivo específico era o estudo de conjuntos lexicais. Nestas atividades, os estudantes eram levados a fazer inferências sobre os significados de novas palavras e a encontrar definições correspondentes a elas. Nestas situações, era possível observar com clareza os três momentos que compõem o modelo teórico aqui utilizado sobre a atividade de ensino - instrução, desenvolvimento e feedback. A professora lia, junto à turma, os pequenos textos onde apareciam as novas palavras e perguntava se eles tinham dúvidas. Em seguida, ela lia os enunciados e explicava-os aos estudantes, para que eles realizassem a tarefa. Depois que eles finalizassem o exercício, a professora corrigia-o coletivamente, tirando dúvidas e dando espaço para que os alunos comentassem sobre suas respostas. A estudante Ana comentou sobre a forma como a professora explicava as dúvidas de vocabulário:

Quando ela pega uma palavra e explica, em inglês mesmo, e a gente consegue entender, eu gosto bastante. Porque aumenta nosso vocabulário e faz com que a gente ligue uma coisa na outra, eu gosto bastante. (Ana).

Ana relatou o fato de a professora buscar explicar o significado das palavras em inglês, não oferecendo a resposta logo de início; segundo ela, isto ajudou a compreender melhor e a ampliar seu vocabulário. Neste sentido, observa-se, ao longo do semestre, que a professora utilizava estratégias diversas para esclarecer as questões de vocabulário dos 
estudantes, como o uso de exemplos, explicações, busca em dicionários e, até mesmo, fazendo mímicas ou gestos.

Ainda sobre este tema, alguns estudantes elogiaram, durante as entrevistas, a postura da professora quando não conhecia alguma palavra que eles lhe perguntavam: ela dizia que não sabia e pesquisava a resposta com os estudantes. Segundo eles, esta atitude tornava-a mais acessível, pois eles não se sentiam pressionados a adotar uma postura de que "sabiam de tudo". Além disto, observa-se que, quando surgiam essas dúvidas, ela buscava as respostas com os estudantes, na internet, utilizando dicionários e outras ferramentas disponíveis online. Esta prática, além de favorecer a aproximação apontada pelos estudantes, também ensinava sobre as formas como eles poderiam solucionar suas dúvidas quando estivessem sozinhos, contribuindo para sua maior autonomia.

\section{Pronúncia}

Assim como o vocabulário, as questões de pronúncia eram tratadas ao longo de outras atividades, mas também foram realizadas algumas atividades específicas sobre o tema. De maneira geral, em ambos os casos, a professora fazia correções e apontamentos sobre a pronúncia, de forma delicada e respeitosa. Durante sua entrevista, ela mencionou que esse era um cuidado que ela tomava, pois sentia que, se interrompesse e corrigisse demais os estudantes, poderia criar um afastamento com a língua. Os estudantes afirmaram que a professora fazia as correções de uma maneira que não os constrangia, ajudando-os a melhorar a pronúncia. Além disso, avaliaram positivamente o uso que a professora fazia de dicionários online para ensinar a pronúncia das palavras:

Eu gosto bastante, principalmente porque no dicionário que ela mostra tem os fonemas. Então, às vezes, de escutar, você não consegue repetir tão bem, mas, vendo os fonemas, você consegue fazer certinho. (Ana).

A professora relatou que buscava mostrar aos estudantes que ter sotaque não é um problema, mas que há pontos na questão da pronúncia que são importantes para que sejam entendidos em sua fala. Neste sentido, houve uma atividade de pronúncia dos verbos na forma do particípio passado, em que alguns estudantes tiveram dificuldade com a pronúncia de "thought" e "taught". A professora utilizou diversos recursos para esclarecer a dúvida, como mostrar os fonemas de cada uma das palavras em sites de pronúncia. Ela 
explicou aos estudantes que eles poderiam sentir a diferença dos sons por uma vibração na garganta e todos experimentaram colocar a mão sobre a garganta ao falar as palavras. Com isso, a professora tentou conscientizá-los sobre como algumas diferenças sutis podem comprometer ou facilitar a comunicação.

\section{Workshop "Saving Indigenous Languages in Western Amazonia"}

Diferentemente das demais atividades, este workshop ocorreu de maneira pontual e consistiu em uma palestra sobre línguas indígenas brasileiras, proferida por uma professora da universidade, a convite da professora Lúcia. O intuito desta atividade foi enriquecer a discussão, disparada pelo livro didático, sobre línguas que estavam desaparecendo. A professora convidada é pesquisadora do assunto e apresentou um projeto de revitalização de línguas indígenas, no Acre. A palestra foi conduzida em inglês e os materiais utilizados na apresentação também estavam neste idioma.

Como continuidade da palestra, a professora Lúcia preparou uma tarefa em que os estudantes deveriam produzir um texto no qual seriam abordados alguns tópicos, tais como: o perfil da palestrante; o conteúdo da apresentação; como foi a experiência de assistir a uma palestra em inglês. Desta forma, como disse a professora Lúcia, o que seria apenas uma palestra foi transformado em um workshop. Em consonância com esta fala, pode-se entender que esta continuidade passou a caracterizar a experiência como uma atividade de ensino, pois compreendeu o desenvolvimento do texto pelos estudantes e o feedback da professora sobre essa produção, além da discussão coletiva sobre o tema do workshop. Em seus textos, os estudantes indicaram que puderam refletir sobre questões de língua, cultura e identidade, aprendendo mais sobre seu próprio país:

(...) the workshop could show me a very different perspective of Brazil. The lecturer has showed me a pluricultural and plurinational Brazil. Besides that, we could realize how language is an important instrument for a people's identity, self-esteem and fight for their own rights. It was remarkable! (Laís).

Esta experiência sugere que a sala de aula de língua inglesa pode ser um espaço privilegiado para a discussão sobre linguagem e poder; no contexto pesquisado, proporcionou uma abordagem mais crítica sobre o papel de uma língua para seu povo. Além disso, os estudantes destacaram que participar desta palestra, conduzida em inglês, 
foi importante para a aprendizagem da língua, pois eles puderam perceber que conseguem acompanhar uma aula neste idioma e alegraram-se com isso. Destacamos, novamente, que esse sentimento de "ser capaz de" favorece a aproximação com o objeto de conhecimento.

\section{Filmes, vídeos e músicas}

Durante as aulas, a professora Lúcia frequentemente fazia sugestões de filmes e/ou de leituras, além de referências a músicas e artistas. Os estudantes, em suas entrevistas, comentam que essas referências e recomendações da professora inspiraram para assistirem a diferentes filmes, lerem livros em inglês e escutarem novos artistas. A professora não apenas recomendava estes conteúdos culturais, mas também os trazia para as aulas. Estes materiais eram utilizados para introduzir temas que seriam abordados ou mesmo em atividades criadas pela própria professora, como a análise de trechos de filmes ou de músicas.

Ao comentarem esta prática da professora Lúcia, os estudantes destacavam a paixão com que ela comentava sobre esses conteúdos, o que os inspirava a conhecerem melhor determinado artista ou a assistirem a algum filme. Portanto, nota-se que esta postura da professora possibilitava aos estudantes engajarem-se com a língua inglesa, inclusive fora da sala de aula, por meio de materiais autênticos e diversos. Miguel avaliou que esta prática da professora contribuía para ampliar o interesse pela língua inglesa:

Ela gosta de trazer coisas que ela é apaixonada também. Tipo um filme que ela gosta, ela fala de um livro, ela mostra coisa na internet... É, isso eu acho importante, por ser a paixão dela. Então, ela passa aquilo pra gente, a gente vai gostar daquilo e vai se interessar mais pelo inglês. Eu acho que é excelente também. (Miguel).

As pesquisas do Grupo do Afeto têm indicado que uma das características do professor que promove uma maior aproximação dos estudantes com o objeto de conhecimento é, justamente, a paixão do professor por aquele objeto que ensina, principalmente quando é percebida pelos alunos. No caso da professora Lúcia, além de os estudantes identificarem a paixão dela pela língua inglesa, eles conheceram também sua paixão pelo cinema, pela literatura, pelas artes plásticas e pela música. O fascínio e o conhecimento de Lúcia por produções culturais, materializados nos conteúdos compartilhados com os estudantes e utilizados em sua prática pedagógica, afetaram 
positivamente as relações dos estudantes com a língua inglesa.

\section{Avaliação}

A escolha dos procedimentos de avaliação é um ponto delicado quando se pensa no planejamento das condições de ensino, podendo ter fortes implicações nas relações dos estudantes com objeto de conhecimento. No caso da professora Lúcia, os estudantes elogiaram a coerência e transparência da docente em relação aos procedimentos avaliativos. Segundo os estudantes, tanto os conteúdos quanto a forma como eles eram cobrados nas provas estavam em consonância com as atividades realizadas durante as aulas. Além disso, os estudantes elogiaram o fato de a professora explicitar claramente os critérios de avaliação. Por exemplo, em uma atividade de apresentação oral, a professora mostrou previamente quais seriam os pontos que ela avaliaria na preparação e na performance da apresentação.

Eu gosto... dos métodos avaliativos dela principalmente, porque ela não leva em consideração só a prova, ela leva em consideração outros tipos de trabalhos, outros tipos de metodologia. E eu gosto da transparência dela no que ela cobra da gente. Ela fala exatamente o que ela vai cobrar e, depois que ela corrige, ela mostra pra gente o que ela esperava da gente. (Michael).

Foi elogiado, igualmente, o fato de que a professora não tardava para fornecer feedback das avaliações, sendo esta devolutiva considerada clara e coerente. Durante a entrevista, a professora afirmou que considera que avaliação caminha junto à prática de sala de aula, seguindo os mesmos princípios norteadores. Destaca-se, ainda, a sensibilidade da professora quanto ao contexto dos estudantes: ela comentou que leva em conta o fato de sua disciplina compor o histórico de graduação dos estudantes e que isto impacta a vida acadêmica deles - na aquisição de bolsas e oportunidades de intercâmbio, por exemplo.

\section{CONSIDERAÇÕES FINAIS}

A análise das práticas pedagógicas da professora Lúcia ajuda a entender por que estas práticas possibilitam uma relação potente, no sentido espinosano, entre estudantes e a 
língua inglesa. A ampla variedade das atividades propostas possibilitou que os estudantes se envolvessem com o curso, mesmo que tivessem objetivos e expectativas diversas com relação ao curso de inglês. Ao se analisarem as atividades desenvolvidas pela professora, destacam-se as relações cultivadas na sala de aula: a relação professora-estudante, marcada pelo respeito e pelo acolhimento; a relação entre estudantes, carregada de companheirismo, encorajada pela professora por meio de suas práticas; a relação de amor da professora pela docência e pela língua inglesa. Todas essas relações, permeadas por sentimentos de alegria, afetam aquela que é a relação central desta pesquisa: a dos estudantes com a língua inglesa. Spinoza (2017) define alegria como o afeto que aumenta a potência de ação do sujeito. Este sentimento foi proporcionado pelas atividades de ensino desenvolvidas, pela postura receptiva e bem-humorada da professora, além de uma visão de linguagem e de educação que proporcionou uma maior aproximação dos aprendizes com a língua inglesa.

Destaca-se que estas potentes práticas pedagógicas são construídas, pelos professores, ao longo de suas carreiras, por meio da sua formação, do trabalho coletivo com outros professores e do contínuo processo de revisão e aperfeiçoamento de suas posturas em sala de aula. Neste sentido, ressalta-se que conhecer a história de constituição da professora Lúcia permitiu aos pesquisadores compreenderem que sua prática docente, admirada pelos estudantes, está relacionada com as situações de mediação, por ela vivenciada, durante todo seu processo de desenvolvimento profissional, incluindo formação inicial e continuada (ORLANDO; LEITE, 2018).

Com base em Leite (2018) e em Swain, Kinnear e Steinman (2011), compreendese que o sucesso na aprendizagem vai além da apropriação dos conteúdos ou do uso acurado da língua; envolve também a construção de vínculos afetivos com o objeto de conhecimento, e, no caso, sentir-se bem consigo mesmo ao usar a língua inglesa. $\mathrm{Na}$ presente pesquisa, tal relação afetiva é claramente ilustrada pela relação de Lúcia com a língua inglesa, plenamente percebida pelos alunos e determinante dos vínculos, também observados, na relação entre os estudantes e as práticas com a língua inglesa desenvolvidas em sala de aula.

Desta forma, defende-se que não é mais possível, também no sentido ético e político, planejar e desenvolver um trabalho pedagógico que envolva relações punitivas 
entre estudantes e objetos de conhecimento. Em outras palavras, o planejamento e o desenvolvimento de práticas pedagógicas precisam prever as possíveis implicações afetivas nas relações que se estabelecerão entre os alunos e os respectivos objetos. Esta concepção direciona a revisão da organização dos espaços, relações e tempos escolares. Neste sentido, pesquisas sobre afetividade e práticas pedagógicas, como aqui relatada, contribuem à área de ensino de línguas ao mostrarem que práticas diferenciadas - que integrem a apropriação do conhecimento às relações de aproximação afetiva - são possíveis. Destaca-se, ainda, a relevância da descrição de práticas pedagógicas, uma vez que é neste cenário - a sala de aula - que as ideias se concretizam.

\section{REFERÊNCIAS}

BAKHTIN, M. M./VOLOCHÍNOV, V. N. Estética da Criação Verbal. São Paulo: Martins Fontes, 2003.

GARZELLA, F. A. C. A disciplina de cálculo 1: análise das relações entre as práticas pedagógicas do professor e seus impactos no aluno. Tese de Doutorado, Faculdade de Educação, UNICAMP. Campinas, SP, 2013.

LEITE, S. A. Afetividade nas práticas pedagógicas. Temas em Psicologia. Sociedade Brasileira de Psicologia, vol 20, no. 2, 355-368, 2012.

Afetividade: as marcas do professor inesquecível (org.). Campinas, SP: Mercado de Letras, 2018.

MAHONEY; ALMEIDA (orgs.). A constituição da pessoa na proposta de Henri Wallon. São Paulo: Edições Loyola, 2004.

ORLANDO, I. R.; LEITE, S. A. S. A história de constituição de uma professora de inglês. Revista Linha Mestra, n 36, p.761-764, 2018. Disponível em: <http://lm.alb.org.br/index.php/lm/article/view/228/250>. Acesso em 03 ago. 2020.

Afetividade e ensino de língua inglesa: um olhar para as práticas pedagógicas. 2019. Dissertação (mestrado) - Universidade Estadual de Campinas, Faculdade de Educação, Campinas, SP. Disponível em: <http://www.repositorio.unicamp.br/handle/REPOSIP/334405>. Acesso em: 03 ago. 2020.

PENNYCOOK, A. The cultural politics of English as an international language. Nova York: Longman, 1994. 
RODRIGUES, A. L. A língua inglesa na África: opressão, negociação e resistência. Campinas: Editora da Unicamp, 2011.

QUAST, K.; BANKS-LEITE, L. Da linguagem ao discurso: memória de práticas e ensino de língua estrangeira. In: SMOLKA, A. L. B. S.; NOGUEIRA, A. L. H. (orgs.) Emoção, memória, imaginação: a constituição do desenvolvimento humano na história e na cultura. Campinas: Mercado de Letras, 2011.

RAJAGOPALAN, K. Emotion and Language Politics: The Brazilian Case. Journal of Multilingual and Multicultural Development, 25:2-3, p. 105-123, 2004. DOI: $<10.1080 / 01434630408666524>$

SPINOZA, B. Ética. Tradução de Tomaz Tadeu. Belo Horizonte: Autêntica Editora, 2017.

SWAIN, M. The inseparability of cognition and emotion in second language learning. Language Teaching, 46, p. 195-207. Cambridge: Cambridge University Press, 2013.

SWAIN, M.; KINNEAR, P.; STEINMAN, L. Sociocultural Theory in Second Language Education: An introduction through narratives. Edição ebook Kindle. Bristol: Multilingual Matters, 2011.

VIGOTSKI, L. S. A Construção do Pensamento e da Linguagem. Tradução Paulo Bezerra. São Paulo: Martins Fontes, 2009

. Obras escogidas. Tomo III. Madrid: Machado Grupo de Distribución, 2012.

VOLÓCHINOV, V. Marxismo e filosofia da linguagem: problemas fundamentais do método sociológico da ciência da linguagem. Tradução de Sheila Grillo. São Paulo: Editora 34, 2017.

WALLON, H. Do acto ao pensamento. Lisboa: Moraes Editores, 1979. . As origens do caráter na criança. São Paulo: Nova Alexandrina, 1995.

Recebido em: 27 jun. 2020. Aceito em: 06 ago. 2020. 